\title{
Libertas: a phase II placebo-controlled study of NRL001 in patients with faecal incontinence showed an unexpected and sustained placebo response
}

\author{
L. Siproudhis ${ }^{1}$ - W. Graf ${ }^{2}$ - A. Emmanuel ${ }^{3}$ - D. Walker ${ }^{4}$ - R. Ng Kwet Shing ${ }^{4}$. \\ C. Pediconi ${ }^{4}$. J. Pilot ${ }^{4} \cdot$ S. Wexner ${ }^{5}$. J. Scholefield ${ }^{6}$
}

Accepted: 4 April 2016/Published online: 13 April 2016

(C) The Author(s) 2016. This article is published with open access at Springerlink.com

\begin{abstract}
Purpose Faecal incontinence (FI) is distressing, significantly reduces quality of life (QoL) and has few pharmacological treatments. The $\alpha_{1}$-adrenoceptor agonist NRL001 (1R,2Smethoxamine hydrochloride) improves anal sphincter tone. NRL001 efficacy was evaluated by changes in Wexner scores at week 4 vs. baseline in NRL001-treated patients compared with placebo. Impact of NRL001 on QoL and safety were also assessed.

Methods Four hundred sixty-six patients received NRL001 $(5,7.5 \mathrm{or} 10 \mathrm{mg})$ or placebo as suppository, once daily over 8 weeks. Wexner score, Vaizey score and QoL were analysed at baseline, week 4 and week 8 . FI episodes and adverse events were recorded in diaries.
\end{abstract}

\footnotetext{
What does this paper add to the literature? All patients' FI symptoms improved, but the NRL001 effect was not significant when compared with placebo. Unexpected and sustained symptom improvements in the placebo group highlight the requirement for appropriate study design. Devices used to treat FI are often introduced without placebo-controlled studies. The use of suppositories is an acceptable and tolerable treatment option for FI patients.
}

D. Walker

dwalker@norgine.com

CHU Pontchaillou, Rennes, France

2 Institution of Surgical Sciences, Akademiska Sjukhuset, Uppsala University, 75185 Uppsala, Sweden

3 University College Hospital, 235 Euston Road, London, UK

4 Norgine Ltd, Norgine House, Widewater Place, Moorhall Road, Uxbridge UB9 6NS, UK

5 Cleveland Clinic Florida, Weston, FL, USA

6 Division of Surgery, University Hospital Nottingham, Nottingham, UK
Results At week 4, mean reductions in Wexner scores were $-3.0,-2.6,-2.6$ and -2.4 for NRL001 5, 7.5, $10 \mathrm{mg}$ and placebo, respectively. All reduced further by week 8 . As placebo responses also improved, there was no significant treatment effect at week $4(p=0.6867)$ or week $8(p=0.5005)$. FI episode frequency improved for all patients, but not significantly compared with placebo (week $4: p=0.2619$, week 8: $p=0.5278$ ). All patients' QoL improved, but not significantly for all parameters $(p>0.05)$ except depression/self-perception at week $4(p=0.0102)$ and week $8(p=0.0069)$, compared with placebo. Most adverse events were mild and judged probably or possibly related to NRL001.

Conclusions All groups demonstrated improvement in efficacy and QoL compared with baseline. NRL001 was well-tolerated without serious safety concerns. Despite the improvement in all groups, there was no statistically significant treatment effect, underlining the importance of relating results to a placebo arm.

Keywords Faecal incontinence $\cdot$ Quality of life $\cdot$ Episode frequency $\cdot$ Alpha-1 receptor agonist $\cdot$ NRL001

\section{Introduction}

Faecal incontinence (FI) is a distressing condition defined as the inability to voluntarily control the passage of faecal matter or gas through the anal canal and expel it at a socially acceptable time and location [1]. It significantly reduces psychological and emotional well-being and negatively affects quality of life (QoL) $[2,3]$. The feelings of embarrassment and depression may be one of the explanations why the majority of patients do not report FI to their physician [4] and may be one of the main reasons why only approximately one third of symptomatic 
patients seek medical help [5]. Estimates of the prevalence of FI vary depending on the population studied. One survey of adults living in the US community showed that approximately $8.3 \%$ reported FI [6]. The incidence of FI has been shown to be significantly higher in women $[7,8]$, in patients with existing gastroenterological conditions [8] and also significantly increases with age $[9,10]$. The most recent and largest North American study found that almost $20 \%$ of healthy women had experienced FI during the preceding 12 months [9].

Mild FI may be improved with conservative therapies including lifestyle changes and biofeedback retraining. Pharmacological interventions remain poorly investigated, and a recent review of clinical trials suggests that many therapies do not significantly improve symptoms [11]. Surgery is increasingly performed in FI due to the failure of conservative and pharmacological therapies. However, many subjects are poor surgical candidates and long-term success rates are variable [12-14]. The lack of a universally effective, surgical method has led to the development of numerous complex options including an artificial bowel sphincter, magnetic anal sphincter, stimulated graciloplasty and sacral nerve stimulation [15-18]. These procedures might lead to definite improvement, but the morbidity profiles emphasize the need for effective pharmacological treatments.

The internal anal sphincter (IAS) muscle exists in a natural state of tonic contraction. Naturally occurring degeneration due to ageing can result in a loss of smooth muscle tone, and in addition, reduced contractile function might lead to uncontrollable bowel movements [19]. The IAS muscles receive excitatory innervations to mediate contraction or relaxation via the $\alpha$-or $\beta$-adrenergic receptors, respectively. Therefore, the adrenergic sympathetic nervous system could be targeted therapeutically with a view to restoring smooth muscle tone and improving FI symptoms [20].

Topical application of the selective $\alpha_{1}$-adrenoceptor agonist phenylephrine increased anal sphincter tone as measured by mean anal resting pressure (MARP) in both healthy subjects and patients with FI [21, 22]. Symptomatic improvement, however, was disappointing in a separate phenylephrine study [23]. 1R,2S-Methoxamine hydrochloride (NRL001) is a highly selective $\alpha_{1}$-adrenoceptor agonist that is approximately four times more potent than phenylephrine at constricting porcine IAS tissue in vitro [24]. Local administration of NRL001 to healthy subjects and patients with FI has been shown to increase MARP [25-27].

Therefore, the Libertas study - a multi-centre, double-blind, randomized, placebo-controlled, dose-ranging clinical study - was designed to primarily investigate the impact of NRL001 on FI symptoms [28]. Secondary aims were to assess patient QoL, safety profile and tolerability.

\section{Methods}

\section{Ethics}

Independent Ethics Committees approved this study, which was conducted in accordance with Good Clinical Practice and the Declaration of Helsinki, 2008. All patients provided written informed consent prior to enrolment. This study was registered at ClinicalTrials.gov (NCT01656720).

\section{Study population}

Patients aged 18 years or more with a diagnosis of FI (Wexner score of 8-20 [29]) and an intact IAS on ultrasonography were eligible for inclusion. Patients had to have FI for at least 6 months and two or more diary confirmed FI episodes per week in the 4 weeks prior to screening. Patients were excluded if there was evidence of external anal sphincter trauma, which allowed for a more homogenous patient population by reducing variation in anal tone and defects. Patients with uncontrolled gastrointestinal, cardiovascular or obstructive pulmonary diseases were excluded. Those suffering from chronic liver disease, renal impairment or closed-angle glaucoma or other conditions of light sensitivity and/or mydriasis were also excluded. The patient demographics are described in Table 1.

\section{Study design}

In brief, this was a multi-centre, phase II, double-blind, randomized, placebo-controlled, parallel group, dose-ranging study (Fig. 1). Patients were randomized in a 1:1:1:1 ratio as follows: NRL001 $5 \mathrm{mg}, 7.5 \mathrm{mg}, 10 \mathrm{mg}$ or placebo in a 2-g suppository to be self-administered once daily [28]. These doses were based on results of a previous study of NRL001 in healthy volunteers [30].

This study was conducted from $27^{\text {th }}$ of February 2012 to $30^{\text {th }}$ of December 2013, in 55 European centres in the Czech Republic, France, Germany, Hungary, Italy, Poland, Spain, Sweden and the UK.

Patients were assigned a unique number based on the study site number and the serial number of the patient at screening. During randomization, eligible patients were assigned a unique randomization number from the Interactive Web Response System (IWRS; Premier Research Group Ltd, UK) that was linked to two patient investigational medicinal product packs. The investigator maintained a list of patient names, assigned unique patient numbers and associated assigned unique randomization numbers. The passwordprotected randomization list was supplied by a statistician of Premier Research Group Ltd using the Statistical Analysis System (SAS) for Windows (SAS Institute Inc., USA) to Pharmaceutical Development, Norgine Ltd, UK. NRL001 
Table 1 Summary of patient demographic characteristics (safety population)

\begin{tabular}{|c|c|c|c|c|c|c|}
\hline \multicolumn{2}{|l|}{ Variable } & \multirow{2}{*}{$\begin{array}{l}\begin{array}{l}\text { NRL001 } 5 \mathrm{mg} \\
(N=114)\end{array} \\
61.4(12.37)\end{array}$} & \multirow{2}{*}{$\begin{array}{l}\text { NRL001 } 7.5 \mathrm{mg} \\
(N=115)\end{array}$} & \multirow{2}{*}{$\begin{array}{l}\text { NRL001 } 10 \mathrm{mg} \\
(N=122)\end{array}$} & \multirow{2}{*}{$\begin{array}{l}\begin{array}{l}\text { Placebo } \\
(N=112)\end{array} \\
61.4(11.39)\end{array}$} & \multirow{2}{*}{$\begin{array}{l}\begin{array}{l}\text { Total } \\
(N=463)\end{array} \\
62.1(12.32)\end{array}$} \\
\hline Age, years & & & & & & \\
\hline \multirow[t]{2}{*}{ Sex, $n(\%)$} & Female & $98(86.0)$ & $99(86.1)$ & $102(83.6)$ & $91(81.3)$ & $390(84.2)$ \\
\hline & Male & $16(14.0)$ & $16(13.9)$ & $20(16.4)$ & $21(18.8)$ & $73(15.8)$ \\
\hline BMI $\left(\mathrm{kg} / \mathrm{m}^{2}\right)$ & & $26.4(4.38)$ & $26.6(4.41)$ & $26.8(4.99)$ & $27.2(4.74)$ & $26.8(4.64)$ \\
\hline Height (cm) & & $164.1(8.36)$ & $163.2(7.53)$ & $164.2(8.37)$ & $165.2(8.61)$ & $164.1(8.23)$ \\
\hline Weight (kg) & & $71.2(13.80)$ & $70.07(11.82)$ & $72.3(14.26)$ & $74.2(14.75)$ & $72.1(13.73)$ \\
\hline \multirow[t]{4}{*}{ Ethnicity, $n \%$} & White & $110(96.5)$ & $113(98.3)$ & $116(95.1)$ & $106(94.6)$ & 445 (96.1) \\
\hline & $\begin{array}{l}\text { Black or } \\
\text { African- } \\
\text { American }\end{array}$ & $1(0.9)$ & $0(0.0)$ & $0(0.0)$ & $1(0.9)$ & $2(0.4)$ \\
\hline & Asian & $0(0.0)$ & $0(0.0)$ & $1(0.8)$ & $1(0.9)$ & $2(0.4)$ \\
\hline & Other & $3(2.6 \%)$ & $2(1.7)$ & $5(4.1)$ & $4(1.3$ & $14(3.0)$ \\
\hline
\end{tabular}

Unless noted otherwise, values are expressed as mean (standard deviation)

$n$ number of patients, $B M I$ body mass index

and placebo were packed and labelled according to pertinent regulations by the Sponsor. The randomization schedule was then made available to the Premier Research Group Ltd IWRS.

This was a double-blind study with all NRL001 and placebo suppositories provided in the same packaging and labelling. No person involved in conducting the study had access to the randomization code before the blinding was officially broken. However, in the case of an emergency that required the investigator to be unblinded, the investigator was allowed to obtain the randomization code via the IWRS.

The study period consisted of a 2-week run-in phase, an 8week treatment period and a 1-week post-treatment follow-up.
In total, the study comprised five visits to the study site. Patients were screened on day 14. On day 1 (randomization), patients received their first dose, provided the eligibility criteria were met. Patients attended visits at week 2, week 4 and week 8. A follow-up telephone call was made at week 9 to assess overall patient satisfaction and the duration of any adverse event.

Patients received 70 suppositories in total-35 at week 1 and 35 at week 4 - and were provided with an electronic diary (e-Diary) to record details of suppository administration and frequency and type of incontinence episodes.

The primary endpoint of this study was to determine the efficacy of NRL001 as assessed by a change in the Wexner

Fig. 1 The Libertas study design

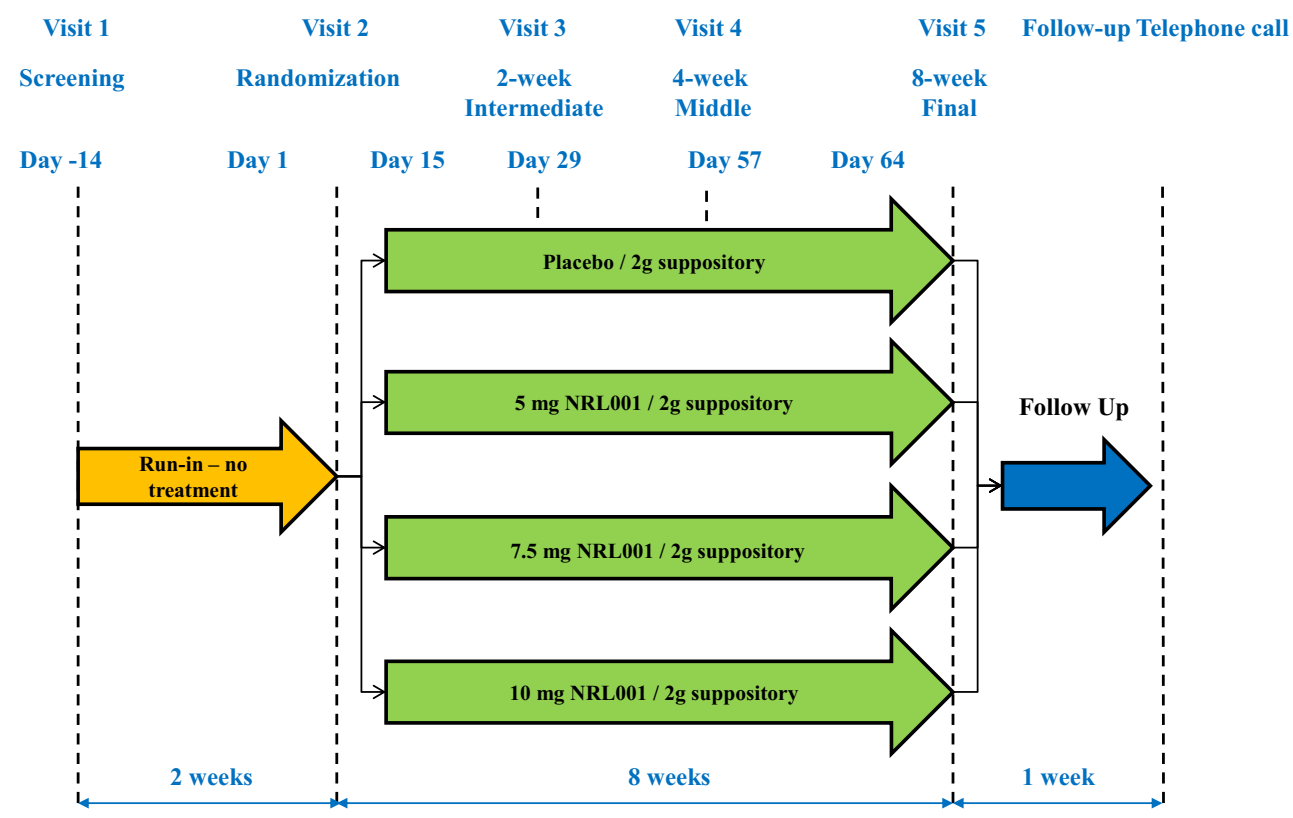


score at week 4 in patients receiving NRL001 compared with those receiving placebo. Key secondary endpoints included Vaizey scores and the number of FI episodes per week as additional efficacy parameters at week 4 and week 8 , as well as patient $\mathrm{QoL}$ and satisfaction.

\section{Sample collection and analysis}

The Wexner scoring system consisted of the score sum of five parameters (frequency of gas, liquid or solid incontinence, need to wear a pad and lifestyle alterations) scored on a scale of 0 (absent) to 4 (daily) [29]. A total score of 0 suggested full continence and score of 20 complete FI. The Vaizey scoring system was subsequently created by modifying to include two additional questions assessing the ability to defer defecation and use of antidiarrheal medication [31]; 0 suggested full continence and 24 complete FI.

QoL was measured using the FI quality of life (FIQoL) scale [2] and the EQ-5D-5L Healthcare Questionnaire [32, 33] at baseline, week 4 and week 8 . The FIQoL scale ranged from 1 to 5, where 1 indicated lowest QoL and 5 the highest, and was produced by scoring statements based on lifestyle, coping/behaviour, depression/self-perception and embarrassment. The EQ-5D-5L Healthcare Questionnaire assessed five parameters: mobility, self-care, ability to perform usual activities, pain/discomfort and anxiety/depression. It also included a visual analogue scale (VAS) for patients to record their self-rated health state. The frequency of FI episodes was assessed using recordings made in the e-Diaries.

Pharmacokinetic relationships between NRL001 concentration and either efficacy or adverse effects were assessed at week 1 (pre-dose and 1, 2 and 4 h post-dose) and week 4.

\section{Safety assessment}

Adverse events were recorded from screening until the end of the study and were coded using MedDRA Version 14.0 or higher. All adverse events were graded as mild, moderate or severe according to intensity, and the relationship to NRL001 was classified as probable, possible or unrelated. The final phone call was used to assess the patients' global perception of efficacy and the duration of adverse events.

Blood pressure, pulse rate, physical examination, urine analysis and 12-lead electrocardiogram measurements were recorded at each visit. Twenty-four-hour Holter monitoring was performed at screening and week 2 . Patients also had blood samples taken at screening, week 2 and week 8 for laboratory safety tests of clinical chemistry and haematology.

\section{Statistical analysis}

The sample size was calculated using a responder rate. Active treatment was classed as a success if it showed a $20 \%$ improvement over placebo in the primary endpoint. With $80 \%$ power and a two-sided level of significance of 0.05 $(5 \%)$, a minimum of 98 patients were required in each treatment group to show a difference between rates of 25 and $45 \%$.

The primary endpoint was defined as the change relative to baseline in Wexner score at week 4. Variation amongst the four treatment groups was tested using an analysis of covariance (ANCOVA) with screening as covariate, and statistical significance was defined as $p<0.05$. Differences between placebo and each of the three active treatment groups are presented with a $95 \%$ confidence interval $(\mathrm{CI})$. Where significant variation was seen, pairwise differences between placebo and each of the three active treatment groups were tested by calculating CIs for the difference in least square means between placebo and active treatment using Dunnett's method within the ANCOVA. Differences in the number of FI episodes and the Vaizey, and FIQoL scores were tested using the same statistical methods as the primary endpoint. Changes in the EQ-5D-5L questionnaire from screening to week 4 and week 8 , and the overall assessment of patient satisfaction at week 9 were tested using the Wilcoxon test.

Plasma concentrations of NRL001 were summarized for each treatment group, and the relationship between estimated areas under the concentration-time curve (AUC) determined.

Study populations included the safety population, all patients who received any dose of NRL001 or placebo; the modified intent to treat (mITT) population, which was used to analyse efficacy and QoL, and included all patients who received any dose of NRL001 or placebo and had data on the Wexner score at both screening and week 4; and the pharmacokinetic population, all patients who received any dose of NRL001 and had valid pharmacokinetic data.

\section{Results}

\section{Patients}

Approximately 580 patients were planned to be screened to obtain 400 evaluable patients. A total of 466 patients were randomized and 463 (safety population) received at least one dose of NRL001 (5 mg, $n=114 ; 7.5 \mathrm{mg}, n=115 ; 10 \mathrm{mg}$, $n=122)$ or placebo $(n=112$, Fig. 2$)$. The mean age was 62.1 years and the majority were female $(390 / 463$ [84 \%], Table 1). The mITT population comprised 440 patients (NRL001 $5 \mathrm{mg}, n=108 ; 7.5 \mathrm{mg}, n=108 ; 10 \mathrm{mg}, n=117$ and placebo $n=107)$. A total of 23 patients from the safety population were excluded from the mITT population (15 because of missing data on the Wexner score at baseline and/or week 4 , and a further eight patients were excluded as a consequence of GCP deviations at one particular study 
Fig. 2 Consort patient flow diagram

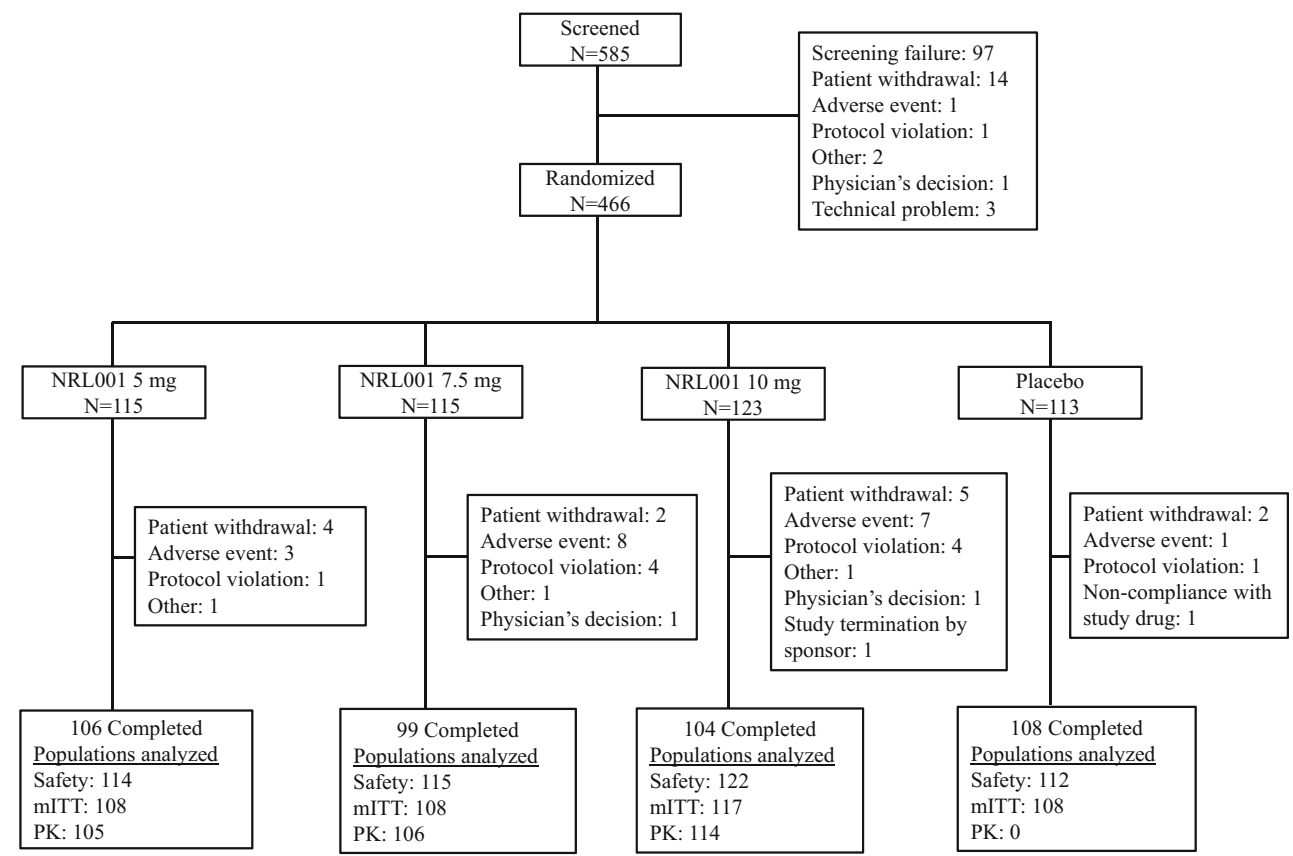

centre). The pharmacokinetic population comprised 325 patients (NRL001 $5 \mathrm{mg}, n=105 ; 7.5 \mathrm{mg}, n=106$; and $10 \mathrm{mg}, n=114)$.

\section{Efficacy}

At baseline, mean Wexner scores were similar between the NRL001 and placebo groups (12.9 \pm 3.1 for NRL001 $5 \mathrm{mg}$, $13.3 \pm 3.2$ for NRL001 $7.5 \mathrm{mg}, 13.3 \pm 3.1$ for NRL001 $10 \mathrm{mg}$ and $12.9 \pm 3.0$ for placebo, Table 2). No statistically significant treatment effect was detected at week 4 or week 8 (Fig. 3).

Vaizey scores and the number of FI episodes per week decreased from screening to week 4 for all treatment groups and had decreased further by week 8 . However, no statistically significant treatment effect was detected (Table 2). Responses in the placebo-treated group were similar to those receiving NRL001 and persisted through the 8-week study period.

\section{Quality of life}

At baseline, mean FIQoL scores were similar for NRL001 and placebo groups in all four parameters (Fig. 4). Scores for each parameter increased in all treatment arms at week 4 and increased further by week 8 . Statistically significant improvements of NRL001 treatment effects compared with placebo were observed on depression/self-perception at week 4 $(p=0.0102)$ and week $8(p=0.0069)$ but not for the other scales $(p>0.05)$. Analysis of $95 \%$ CIs revealed a statistically significant treatment difference between NRL001 $5 \mathrm{mg}$ and placebo for depression/self-perception at both week 4 (treatment difference 0.25 [95\% CI $0.06-0.44]$ ) and week 8 (treatment difference 0.28 [95 \% CI 0.08-0.47]) but not for other doses.

There was a significant increase in overall assessment of health according to the VAS at week 4 in all NRL001 treatment groups compared with placebo $(p=0.0478)$, but VAS was not significantly improved at week 8 in any of the treatment groups compared with placebo $(p>0.05$, data not shown). Analysis of EQ-5D-5L data showed marginal differences compared with placebo at week 4 and week 8 for some of the parameters (Table 3).

\section{Pharmacokinetics}

There was a dose-dependent increase in the plasma concentration of NRL001 with mean AUC values of $15.4 \pm 8.7 \mathrm{ng} /$ $\mathrm{mL} / \mathrm{h}$ for NRL001 $5 \mathrm{mg}, 23.9 \pm 12.9 \mathrm{ng} / \mathrm{mL} / \mathrm{h}$ for NRL001 $7.5 \mathrm{mg}$ and $32.2 \pm 17.0 \mathrm{ng} / \mathrm{mL}$ for NRL001 $10 \mathrm{mg}$ (pharmacokinetic population). No NRL001 was detected in the placebo-treated group (data not shown).

\section{Patient satisfaction}

Seventy-one (82.6\%), $59(74.7 \%)$ and $72(75.8 \%)$ patients who received NRL001 5, 7.5 and $10 \mathrm{mg}$, respectively, and 77 $(85.6 \%)$ patients who received placebo said they would choose to take the same medication again. There were no statistically significant differences between NRL001 groups and placebo $(p>0.05)$ for overall assessment of patient satisfaction (performance of study medication; taking study medication again and the change in QoL). 


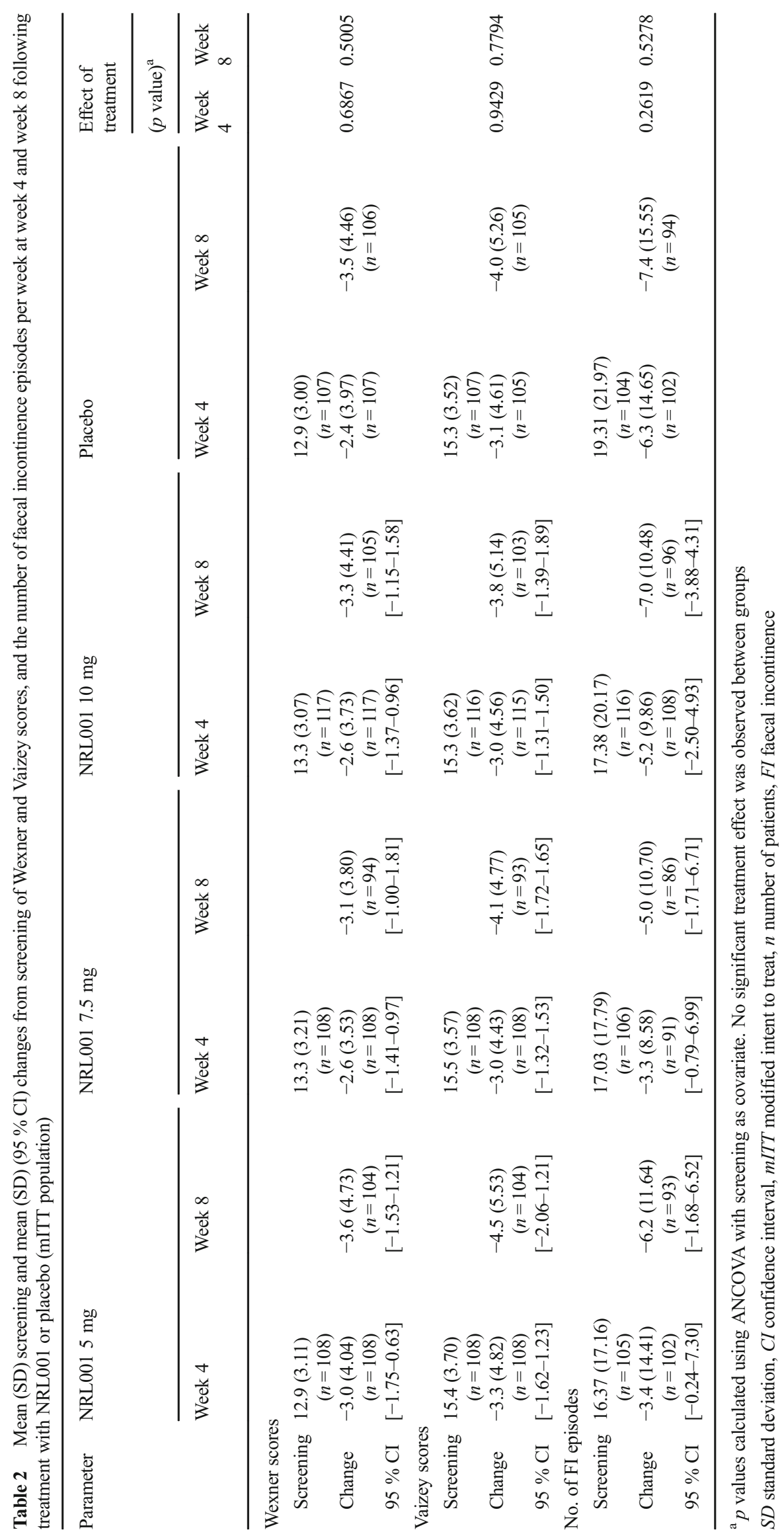




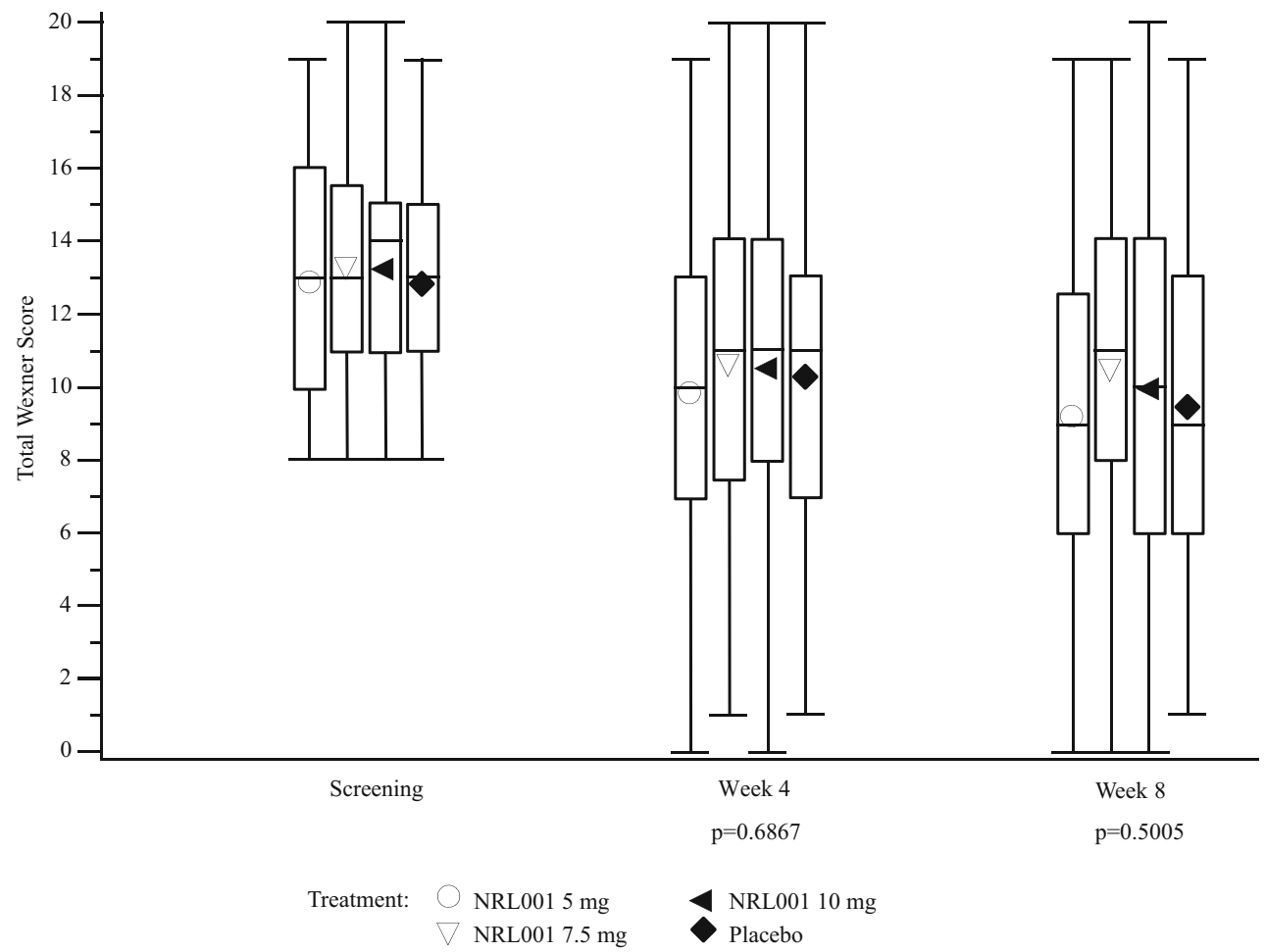

Fig. 3 Patients' Wexner scores at screening, week 4 and week 8 (mITT population). Symbols are the means, boxes are the interquartile range, lines within the boxes are the median and whiskers are the range. No

significant treatment effect of the change from screening was observed at week 4 or week 8 ( $p$ values calculated using ANCOVA with screening as covariate)
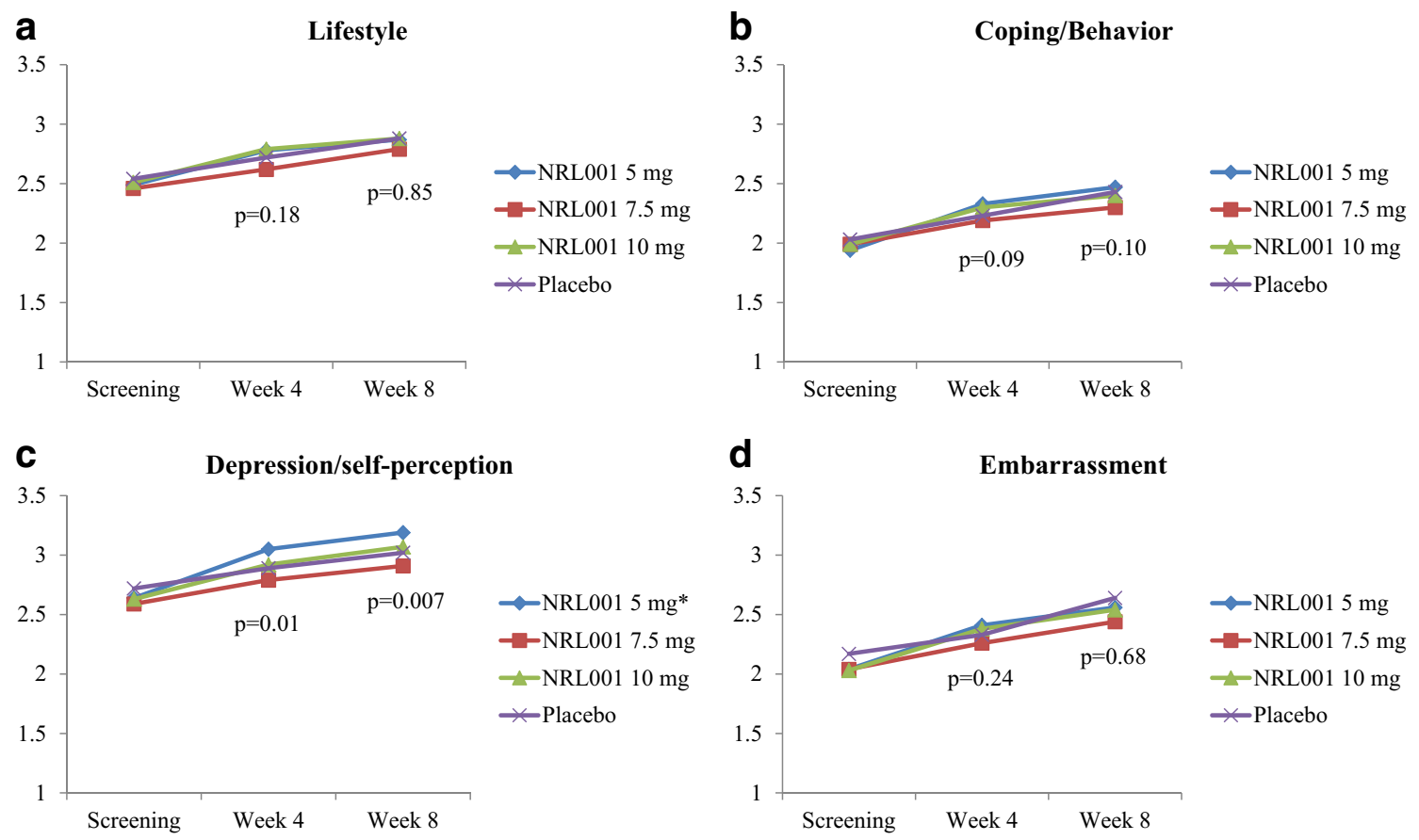

Fig. 4 Patients' mean FIQoL scores at screening, week 4 and week 8 (mITT population) for the four parameters: lifestyle (a), coping/ behaviour (b), depression/self-perception (c) and embarrassment (d). $p$ values for treatment effects calculated using ANCOVA with

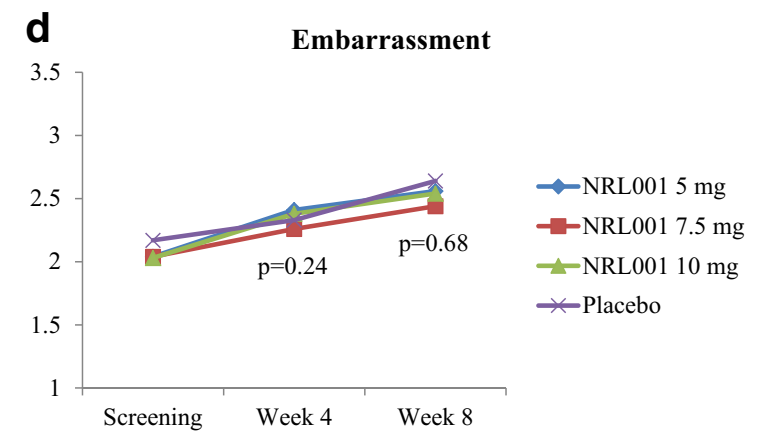

screening as covariate. *Pairwise differences between placebo and NRL001 $5 \mathrm{mg}$ were statistically significant at both week 4 and week 8 at the $95 \%$ CI, calculated using Dunnett's method within ANCOVA 
Table 3 Wilcoxon $p$ values calculated for the change in Questionnaire from screening at week 4 and week 8 (mITT population) the EQ-5D-5L Healthcare

\begin{tabular}{llll}
\hline \multirow{2}{*}{ Question } & Comparison of & \multicolumn{2}{l}{ Wilcoxon $p$ value } \\
\cline { 2 - 3 } & NRL001 vs. placebo & Week 4 & Week 8 \\
\hline Mobility & $5 \mathrm{mg}$ & 0.00353 & 0.34432 \\
& $7.5 \mathrm{mg}$ & 0.16309 & 0.68848 \\
& $10 \mathrm{mg}$ & 0.05261 & 0.78593 \\
Self-care & $5 \mathrm{mg}$ & 0.12285 & 0.32080 \\
& $7.5 \mathrm{mg}$ & 0.07852 & 0.49652 \\
& $10 \mathrm{mg}$ & 0.44415 & 0.61766 \\
Activity & $5 \mathrm{mg}$ & 0.0007561 & 0.03675 \\
& $7.5 \mathrm{mg}$ & 0.06087 & 0.02401 \\
& $10 \mathrm{mg}$ & 0.02297 & 0.13918 \\
Pain & $5 \mathrm{mg}$ & 0.15276 & 0.28540 \\
& $7.5 \mathrm{mg}$ & 0.33317 & 0.57655 \\
& $10 \mathrm{mg}$ & 0.14695 & 0.38680 \\
Anxiety/depression & $5 \mathrm{mg}$ & 0.18180 & 0.07648 \\
& $7.5 \mathrm{mg}$ & 0.73124 & 0.68457 \\
& $10 \mathrm{mg}$ & 0.34466 & 0.94216 \\
\hline
\end{tabular}

mITT modified intent to treat

\section{Safety}

Overall, 212/463 (46\%) patients reported 494 adverse events (Table 4). In general, more patients in the NRL001-treated groups were affected by adverse events $(45.2-52.5 \%$ ) than those who received placebo $(36.6 \%)$. The most frequent adverse events following dosing with NRL001 (paraesthesia, feeling cold and piloerection) were expected, generally mild in intensity and judged to be attributed to the pharmacological effect of NRL001, but the relationship between adverse events and efficacy of NRL001 was not explored.

Eighteen patients (3.9\%) experienced adverse events leading to withdrawal from the study, and 20 patients $(4.3 \%)$ experienced adverse events that led to discontinuation of the study drug. The number of patients whose adverse events led to discontinuation of the study drug was higher in the NRL001treated groups than placebo (19/20 receiving NRL001; 1/20 receiving placebo). One patient who received NRL001 $10 \mathrm{mg}$ developed severe cardiac failure following hospitalization from urosepsis that was considered serious and judged possibly related to study drug, although this resolved by the end of the study. There were no reports of bradycardia during the study.

\section{Discussion}

Wexner scores decreased across all NRL001 treatment arms compared with baseline. However, a marked placebo response

Table 4 Adverse events reported by $\geq 3 \%$ of patients (safety population)

\begin{tabular}{|c|c|c|c|c|c|c|c|c|c|c|}
\hline & \multicolumn{2}{|c|}{$\begin{array}{l}\text { NRL001 } 5 \mathrm{mg} \\
(N=114)\end{array}$} & \multicolumn{2}{|c|}{$\begin{array}{l}\text { NRL001 } 7.5 \mathrm{mg} \\
(N=115)\end{array}$} & \multicolumn{2}{|c|}{$\begin{array}{l}\text { NRL001 } 10 \mathrm{mg} \\
(N=122)\end{array}$} & \multicolumn{2}{|l|}{$\begin{array}{l}\text { Placebo } \\
(N=112)\end{array}$} & \multicolumn{2}{|c|}{ Total $(N=463)$} \\
\hline & $n(\%)$ & $e$ & $n(\%)$ & $e$ & $n(\%)$ & $e$ & $n(\%)$ & $e$ & $n(\%)$ & $e$ \\
\hline Any event & $55(48.2)$ & 107 & $52(45.2)$ & 140 & $64(52.5)$ & 162 & $41(36.6)$ & 85 & $212(45.8)$ & 494 \\
\hline Paraesthesia & $9(7.9)$ & 9 & $14(12.2)$ & 18 & $17(13.9)$ & 21 & $1(0.9)$ & 1 & $41(8.9)$ & 49 \\
\hline Headache & $1(0.9)$ & 1 & $6(5.2)$ & 7 & $5(4.1)$ & 5 & $6(5.4)$ & 6 & $18(3.9)$ & 19 \\
\hline Feeling cold & $11(9.6)$ & 11 & $7(6.1)$ & 7 & $12(9.8)$ & 13 & $3(2.7)$ & 4 & $33(7.1)$ & 35 \\
\hline Chills & $8(7.0)$ & 8 & $6(5.2)$ & 8 & $8(6.6)$ & 10 & $0(0.0)$ & 0 & $22(4.8)$ & 26 \\
\hline Piloerection & $5(4.4)$ & 7 & $8(7.0)$ & 9 & $14(11.5)$ & 15 & $0(0.0)$ & 0 & $27(5.8)$ & 31 \\
\hline Urinary tract infection & $4(3.5)$ & 7 & $1(0.9)$ & 1 & $5(4.1)$ & 5 & $4(3.6)$ & 4 & $14(3.0)$ & 17 \\
\hline Other & $17(14.9)$ & 64 & $10(8.7)$ & 90 & $3(2.5)$ & 93 & $27(24.1)$ & 70 & $57(12.3)$ & 317 \\
\hline
\end{tabular}

Includes events occurring in less than $3 \%$ of patients

$n$ number of patients, $e$ number of events 
was observed during the entire 8-week treatment period such that no statistically significant treatment effect was observed when comparing active treatment with placebo. Secondary endpoints showed similar findings, with marked improvements in response to NRL001 accompanied by a notable placebo response of similar magnitude. However, NRL001 had a statistically significant effect on some QoL assessments at week 4 and week 8 compared with placebo: NRL001 significantly improved patients' self-assessed mobility, activity and overall health at week 4 and activity at week 8 . Although these were not paired with statistically significant improvements in Wexner scores, correlations were apparent. Decreases in Wexner and Vaizey scores, and frequency of FI episodes complemented QoL improvements; associations have proven to be significant in previous validation studies [34-36].

The reduction in Wexner score after 8 weeks of treatment when compared with baseline was highly significant for all NRL001 treatment arms $(p<0.0001)$ as well as placebo. Pharmacokinetic data demonstrated a dose-dependent increase in plasma concentrations of NRL001. Visual inspections of the data indicated that there was no dose-proportional improvement in any of the endpoints, although this was not tested statistically. A dose-dependent increase in MARP was reported in a study in which NRL001 was administered to healthy volunteers [27]. Assessment of anorectal physiology may have provided useful information regarding the mechanistic insight of the drug. However, anorectal physiology assessments were likely to have significantly adversely affected enrolment feasibility and cost. Furthermore, evaluations of anorectal physiology, such as anorectal manometry assessments, are often also poorly correlated with patient outcomes $[37,38]$. This has been hypothesized to be due to a stenosing effect following surgery, increasing the resistance to blood flow through the anus, masking physiological alterations detected in pressure measurements [39]. Additionally, MARP was not assessed in this current study due to the difficulties standardizing methodologies in a large patient population and the suggestion that many therapies do not significantly improve symptoms of FI, despite their positive effect on MARP [11]. This and the lack of dose-response in symptom improvement in the current study argue strongly that biological endpoints such as MARP are poor markers of patient outcomes. The FI episodes reported in this study encompassed all forms of incontinence. It was considered that analysis of faecal matter incontinence episodes (FMIE), which excludes flatus, might reveal a more robust treatment effect. Consequently, although not presented here, FMIE for each active treatment group at both week 4 and week 8 were analysed and compared with those of placebo-treated patients but no significant treatment effect was observed. As such, evaluation of Wexner scores as the primary endpoint for this study was considered appropriate.
The reported adverse events were similar to those in previous studies (paraesthesia, chills and piloerection) and were thought to be a direct result of increased $\alpha_{1}$-adrenoceptor stimulation [25-27, 30, 40, 41]. Visual inspections of the data indicated that adverse events were less frequent in the placebo-treated group than any of the NRL001-treated groups. There also appeared to be no dose-relationship in the frequency of adverse events reported across the three active treatment groups, although not tested statistically. Safety assessments did not show any new or previously unknown risks of NRL001. Bradycardia - an expected effect of $\alpha_{1}$-adrenoceptor stimulation [42] — was not reported in any treatment group. A meta-analysis of previous studies involving topical application of NRL001 has shown that whilst patients generally experienced a dose-dependent decrease in heart rate, bradycardia was not clinically significant [43]. Therefore, the safety of NRL001 was deemed better than expected.

The inclusion criteria for this study included a screening Wexner score of 8-20. Therefore, patient FI severities ranged from relatively mild to very severe [29]. It is possible that the severity of Wexner score at screening was an important factor; however, a descriptive post hoc analysis (Norgine data on file) was unable to show any difference in effect between patients with baseline Wexner score of $8-11,12-15$ or $16-20$. This inclusion criterion was designed to make the results of this study comparable with those of other recent studies that assess new therapeutic options for treatment of FI (not direct surgical repair) and use the Wexner score to define their patient population [44-46]. Prior exposure of patients to biofeedback therapy, a conservative approach employed to treat FI based on the theories of operant conditioning, was not taken into consideration. Patients receiving conservative treatments display sustained FI symptom improvement for up to a year, but some studies hypothesize that beneficial effects relate more to the relationship with the therapist than the technical aspects of the therapy and many responders lose the effect over time [47]. It is possible that any patients naive to biofeedback therapy included in this study may have benefited more from inclusion in the study rather than the pharmacological substance itself. Also, any patient in whom biofeedback therapy had previously improved symptoms, but which was lost over time, might be more likely to have improvement in their symptoms again. As such, this study may have benefited by including a run-in period with biofeedback therapy to exclude those patients who would have attained adequate FI symptom relief from conservative treatments. However, this is likely to have restricted the number of patients eligible for inclusion.

A number of important factors made the Libertas study unique: There have been few similarly designed studies in FI involving this number of patients; this study was the first testing NRL001 in a broad population of patients; and it employed innovative strategies, including the use of an 
outreach program, to recruit patients whilst taking into account the sensitivity of the condition [28], and finally the comparison of subjects' responses to NRL001 with placebo, rather than solely with screening measurements. Given the positive effects of NRL001 in previous studies [25-27], the findings of the current study are highly relevant, confirming the importance of a placebo group.

Predictors of the placebo response have been a focus of many studies with potentially significant impact on clinical trials. The placebo response observed in this study was larger than expected and did not decline during the 8-week treatment period. The placebo suppositories used in this study comprised 0.03-g colloidal anhydrous silica and 1.97-g hard fat. NRL001 suppositories contained reduced amounts of fat to compensate for the addition of NRL001. The route of administration of a treatment is known to impact the extent to which a placebo response may be elicited. A review of placebo responses observed in clinical trials of migraine treatments concluded that interventions administered at the site of pain elicit a greater placebo response than those administered at a distance [48]. As such, the placebo response observed in this study is likely to have been more robust than a placebo response observed had the intervention for FI been administered orally. Furthermore, progressively invasive treatments are coupled with a more robust placebo response: One study of a migraine treatment reported pain relief of $39 \%$ following administration of placebo as a suppository, whereas others have demonstrated pain relief of $39-32 \%$ following administration via nasal sprays [48]. Placebo-controlled studies in patients with FI have also shown unexpected high response rates after saline injection [49] or sham electrical stimulations $[50,51]$. As well as the route of administration, the small sample sizes of these studies may have contributed to the lack of clinical effect in these studies. This was one factor that the Libertas study aimed to mitigate, and by using a broad and ample study population, it was hoped that the sample size would be sufficient to demonstrate a significant clinical effect. These findings suggest that FI studies that report a positive treatment effect but do not make comparisons with placebo should perhaps be interpreted with caution.

Treatment-specific restrictions on conservative therapies such as dietary advice, behavioural changes or muscle-strengthening exercises were not imposed on patients during this study. Therefore, active treatment groups and the placebo-treated group should have received similar treatments throughout. Although conservative medical treatments were not analysed here, a Cochrane review of 21 individual studies found little evidence to support the therapeutic benefits of anal sphincter exercises or biofeedback therapy alone [52], and so the use of these by placebo-treated patients would have been unlikely to account for their robust response. Patients were also required to report any concomitant medications taken throughout the study in their e-Dairies.
A total of 17 patients used drugs for the treatment of functional gastrointestinal disorders during the course of the study, although there was imbalance in relation to treatment group. Therefore, the use of concomitant medications or conservative medical treatments was not thought to differ between treatment groups and thus contribute to the response observed in the placebo-treated group.

A recent review suggested that the placebo response is also related to cognitive constructs, such as locus of control-the extent to which individuals believe they can control events $[53,54]$. In particular, a placebo response is seen in those with an external locus of control, meaning participants have a strong belief that outcomes are determined by factors external to their control $[55,56]$. Additional factors that appear to minimize the placebo response in gastroenterology studies are the use of a randomized, double-blind, controlled, parallel group study design, with dosing taking place no more than once daily $[57,58]$, all of which were implemented in this study.

In conclusion, patients in this study displayed an improvement in FI symptoms in all parameters tested throughout the duration of this 8-week study. This was also reflected in improvements of QoL and positive patient satisfaction. However, no statistically significant treatment effects of NRL001 were seen compared with placebo because of the comparable response observed in this group. This finding confirms the importance of robust study design in clinical trials to include appropriate control and comparator groups and should be considered when interpreting other studies in this therapeutic area. Libertas was intended to provide a framework for future studies allowing clear endpoints to be derived. It is hoped that, despite the lack of a treatment effect in the Libertas study, lessons learned from its design and conduct will ultimately benefit patients suffering with FI.

Acknowledgments The authors would like to thank the patients and investigators who participated in the Libertas study. The Libertas study investigators included Milan Siroky, Anna Jungwirthová, Alena Jiroudkova, Pavel Drastich, Pavel Weber, Vitezslav Duchac, Michael Halaška, Jiri Hoch, Laurent Siproudhis, Frank Zerbib, Paul-Antoine Lehur, Francois Mion, Anne-Marie Leroi, Hubert J. Mönnikes, Roland R. Scherer, Joachim Rom, Metin Senkal, Tibor Szalóki, István Altorjay, András I. Rosztóczy, Attila Nagy, Róbert Schnabel, Tibor Kocsár, László Lauf, Zsuzsanna Kallo, Filippo La Torre, Enrico Corazziari, Leonardo Lenisa, Angelo Stuto, Marco Frascio, Paola De Nardi, Maciej Kierzkiewicz, Adam Dziki, Tomasz Blicharski, Jacek J. Śmigielski, Michal Walczak, Henryke Mekle, Marek Horynski, Piotr P. Walega, Joanna J. Piskórz Wapinska, Barbara Wozniak-Stolarska, Glòria Lacima, Mónica Perona, Eloy Espin Basany, Federico Sopena, Pere Clave, Lluis Mundet, Omar Ortega, Wilhelm Graf, Magnus V. Andersson, Marianne Starck, Ulf Gunnarsson, Karin Strigård, Steven Brown, Charles Maxwell-Armstrong, Rudra Maitra, Carolynne Vaizey and Anton Emmanuel. The authors also acknowledge the contributions of A. John Camm, Hans-Juergen Gruss and Jackie Turner (study statistician). Ellen Robertshaw of Niche Science and Technology Ltd. provided medical writing support, which was paid for by Norgine Ltd. 


\section{Compliance with ethical standards}

Guarantor of the article D. Walker accepts responsibility for the integrity of the work as a whole, from inception to published article.

Specific author contributions All authors were involved in the review and interpretation of the data from this study. All authors contributed to development of the manuscript, including critical review, and approved the final version of the article, including the authorship list.

Financial support This study was funded by Norgine. Data analyses were performed by Jackie Turner of Premier Research Group Ltd and funded by Norgine Limited. Writing support was provided by Dr. Ellen Robertshaw of Niche Science and Technology Ltd. (Richmond, UK) and funded by Norgine Limited. D. Walker, R. Ng Kwet Shing, C. Pediconi and J. Pilot are employees of Norgine Limited. J. Scholefield was remunerated by Norgine for his work as Chair of the Data Monitoring Committee.

Competing interests S. Wexner discloses honoraria from Incontinence Devices, Inc., Medtronic, Mederi, and Salix, and stock options from Renew Medical. L. D. Walker, R. Ng Kwet Shing, C. Pediconi and J. Pilot are employees of Norgine Limited. J. Scholefield was remunerated by Norgine for his work as Chair of the Data Monitoring Committee. L. Siproudhis, W. Graf and A. Emmanuel have nothing to disclose.

Open Access This article is distributed under the terms of the Creative Commons Attribution 4.0 International License (http:// creativecommons.org/licenses/by/4.0/), which permits unrestricted use, distribution, and reproduction in any medium, provided you give appropriate credit to the original author(s) and the source, provide a link to the Creative Commons license, and indicate if changes were made.

\section{References}

1. Rao SS (2004) Diagnosis and management of fecal incontinence. Am J Gastroenterol 99:585-604

2. Rockwood TH, Church JM, Fleshman JW et al (2000) Fecal Incontinence Quality of Life Scale: quality of life instrument for patients with fecal incontinence. Dis Colon Rectum 43:9-16

3. Bartlett L, Nowak M, Ho YH (2009) Impact of fecal incontinence on quality of life. World J Gastroenterol 15:3276-3282

4. Bartlett L, Nowak M, Ho YH (2007) Reasons for non-disclosure of faecal incontinence: a comparison between two survey methods. Tech Coloproctol 11:251-257

5. Johanson JF, Lafferty J (1996) Epidemiology of fecal incontinence: the silent affliction. Am J Gastroenterol 91:33-36

6. Whitehead WE, Borrud L, Goode PS et al (2009) Fecal incontinence in US adults: epidemiology and risk factors. Gastroenterology 137 : 512-517

7. Nelson R, Norton N, Cautley E, Furner S (1995) Community-based prevalence of anal incontinence. JAMA 274:559-561

8. Alsheik EH, Coyne T, Hawes SK et al (2012) Fecal incontinence: prevalence, severity, and quality of life data from an outpatient gastroenterology practice. Gastroenterol Res Pract. doi:10.1155/ 2012/947694

9. Brown HW, Wexner SD, Segall MM et al (2012) Accidental bowel leakage in the mature women's health study: prevalence and predictors. Int J Clin Pract 66:1101-1108

10. Perry S, Shaw C, McGrother C et al (2002) Prevalence of faecal incontinence in adults aged 40 years or more living in the community. Gut 50:480-484
11. Omar M, Alexander CE (2013) Drug treatment for faecal incontinence in adults. Cochrane Database Syst Rev. doi:10.1002/ 14651858

12. Kammerer-Doak DN, Dominguez C, Harner K et al (1998) Surgical repair of fecal incontinence. Correlation of sonographic anal sphincter integrity with subjective cure. J Reprod Med 43:576-580

13. Pfeifer J (2004) Quality of life after sphincteroplasty. Acta Chir Iugosl 51:73-75

14. Altomare DF, De Fazio M, Giuliani RT et al (2010) Sphincteroplasty for fecal incontinence in the era of sacral nerve modulation. World J Gastroenterol 16:5267-5271

15. Findlay JM, Yeung JM, Robinson R et al (2010) Peripheral neuromodulation via posterior tibial nerve stimulation - a potential treatment for faecal incontinence? Ann R Coll Surg Eng1 92:385-390

16. Van Koughnett JA, Wexner SD (2013) Current management of fecal incontinence: choosing amongst treatment options to optimize outcomes. World J Gastroenterol 19:9216-9230

17. Barker A, Hurley J (2014) Novel treatment options for fecal incontinence. Clin Colon Rectal Surg 27:116-120

18. Rao SS (2014) Current and emerging treatment options for fecal incontinence. J Clin Gastroenterol 48:752-764

19. Hull T (2007) Fecal Incontinence. Clin Colon Rectal Surg 20:118-124

20. Cook TA, Brading AF, Mortensen NJ (2001) The pharmacology of the internal anal sphincter and new treatments of ano-rectal disorders. Aliment Pharmacol Ther 15:887-898

21. Carapeti EA, Kamm MA, Evans BK et al (1999) Topical phenylephrine increases anal sphincter resting pressure. Br J Surg $86: 267-270$

22. Cheetham MJ, Kamm MA, Phillips RK (2001) Topical phenylephrine increases anal canal resting pressure in patients with faecal incontinence. Gut 48:356-359

23. Carapeti EA, Kamm MA, Phillips RK (2000) Randomized controlled trial of topical phenylephrine in the treatment of faecal incontinence. Br J Surg 87:38-42

24. Jones OM, Thompson JM, Brading AF et al (2003) L-Erythromethoxamine is more potent than phenylephrine in effecting contraction of internal anal sphincter in vitro. Br J Surg 90:872-876

25. Nisar PJ, Gruss HJ, Bush D et al (2005) Intra-anal and rectal application of L-erythro methoxamine gel increases anal resting pressure in healthy volunteers. Br J Surg 92:1539-1545

26. Nisar PJ, Gruss HJ, Bush D et al (2007) Intra-anal application of Lerythro methoxamine gel increases anal resting pressure in patients with incontinence. Br J Surg 94:1155-1161

27. Simpson JA, Bush D, Gruss HJ et al (2014) A randomised, controlled, crossover study to investigate the safety and response of $1 \mathrm{R}$, 2S-methoxamine hydrochloride (NRL001) on anal function in healthy volunteers. Color Dis 16(suppl 1):5-15

28. Siproudhis L, Jones D, Shing RN et al (2014) Libertas: rationale and study design of a multicentre, Phase II, double-blind, randomised, placebo-controlled investigation to evaluate the efficacy, safety and tolerability of locally applied NRL001 in patients with faecal incontinence. Color Dis 16(suppl 1):59-66

29. Jorge JMN, Wexner SD (1993) Etiology and management of fecal incontinence. Dis Colon Rectum 36:77-97

30. Bell D, Duffin A, Jacobs A et al (2014) A double-blind, placebocontrolled, randomised, parallel group, dose-escalating, repeat dose study in healthy volunteers to evaluate the safety, tolerability, pharmacodynamic effects and pharmacokinetics of the once daily rectal application of NRL001 suppositories for 14 days. Color Dis 16(suppl 1):36-50

31. Vaizey CJ, Carapeti E, Cahill JA et al (1999) Prospective comparison of faecal incontinence grading systems. Gut 44:77-80

32. Rabin R, de Charro F (2001) EQ-5D: a measure of health status from the EuroQol Group. Ann Med 33:337-343 
33. Herdman M, Gudex C, Lloyd A et al (2011) Development and preliminary testing of the new five-level version of EQ-5D (EQ-5D-5L). Qual Life Res 20:1727-1736

34. Rothbarth J, Bemelman WA, Meijerink WJ et al (2001) What is the impact of fecal incontinence on quality of life? Dis Colon Rectum 44:67-71

35. Minguez M, Garrigues V, Soria MJ et al (2006) Adaptation to Spanish language and validation of the fecal incontinence quality of life scale. Dis Colon Rectum 49:490-499

36. Rullier E, Zerbib F, Marrel A et al (2004) Validation of the French version of the Fecal Incontinence Quality-of-Life (FIQL) scale. Gastroenterol Clin Biol 28:562-568

37. Zutshi M, Salcedo L, Hammel J et al (2010) Anal physiology testing in fecal incontinence: is it of any value? Int J Color Dis 25:277-282

38. Evans C, Davis K, Kumar D (2006) Overlapping anal sphincter repair and anterior levatorplasty: effect of patient's age and duration of follow-up. Int J Color Dis 21:795-801

39. Osterberg A, Edebol Eeg-Olofsson K, Graf W (2000) Results of surgical treatment for faecal incontinence. Br J Surg 87:1546-1552

40. Bell D, Pediconi C, Jacobs A (2014) Randomised clinical trial: study of escalating doses of NRL001 given in rectal suppositories of different weights. Color Dis 16(suppl 1):16-26

41. Bell D, Duffin A, Gruss HJ et al (2014) A randomised, controlled, crossover study to investigate the pharmacodynamics, pharmacokinetics and safety of 1R,2S-methoxamine hydrochloride (NRL001) in healthy elderly subjects. Color Dis 16(suppl 1):27-35

42. Thiele RH, Nemergut EC, Lynch C 3rd (2011) The Clinical Implications of Isolated Alpha1 Adrenergic Stimulation. Anesth Analg 113:297-304

43. Gruss HJ, Pediconi C, Jacobs A (2014) Meta-analysis for cardiovascular effects of NRL001 after rectal application in healthy volunteers. Color Dis 16(suppl 1):51-58

44. Graf W, Mellgren A, Matzel KE et al (2011) Efficacy of dextranomer in stabilised hyaluronic acid for treatment of faecal incontinence: a randomised, sham-controlled trial. Lancet 377: 997-1003

45. Wong MT, Meurette G, Rodat F et al (2011) Outcome and management of patients in whom sacral nerve stimulation for fecal incontinence failed. Dis Colon Rectum 54:425-432
46. Frascio M, Mandolfino F, Imperatore M et al (2014) The SECCA procedure for faecal incontinence: a review. Color Dis 16:167-172

47. Norton C, Chelvanayagam S, Wilson-Barnett J et al (2003) Randomized controlled trial of biofeedback for fecal incontinence. Gastroenterology 125:1320-1329

48. Speciali JG, Peres M, Bigal ME (2010) Migraine treatment and placebo effect. Expert Rev Neurother 10:413-419

49. Siproudhis L, Morcet J, Lainé F (2007) Elastomer implants in faecal incontinence: a blind, randomized placebo-controlled study. Aliment Pharmacol Ther 25:1125-1132

50. Leroi AM, Parc Y, Lehur PA et al (2005) Efficacy of sacral nerve stimulation for fecal incontinence: results of a multicenter doubleblind crossover study. Ann Surg 242:662-669

51. Leroi AM, Siproudhis L, Etienney I et al (2012) Transcutaneous electrical tibial nerve stimulation in the treatment of fecal incontinence: a randomized trial (CONSORT 1a). Am J Gastroenterol 107: 1888-1896

52. Norton C, Cody JD (2012) Biofeedback and/or sphincter exercises for the treatment of faecal incontinence in adults. Cochrane Database Syst Rev 7, CD002111

53. Heatherton TF, Polivy J, Herman CP (1989) Restraint and internal responsiveness: effects of placebo manipulations of hunger state on eating. J Abnorm Psychol 98:89-92

54. Horing B, Weimer K, Schrade D et al (2013) Reduction of motion sickness with an enhanced placebo instruction: an experimental study with healthy participants. Psychosom Med 75:497-504

55. Vase L, Robinson ME, Verne GN et al (2005) Increased placebo analgesia over time in irritable bowel syndrome (IBS) patients is associated with desire and expectation but not endogenous opioid mechanisms. Pain 115:338-347

56. Flaten MA, Aslaksen PM, Finset A et al (2006) Cognitive and emotional factors in placebo analgesia. J Psychosom Res 61:81-89

57. Spiller RC (1999) Problems and challenges in the design of irritable bowel syndrome clinical trials: experience from published trials. Am J Med 107:91S-97S

58. Pitz M, Cheang M, Bernstein CN (2005) Defining the predictors of the placebo response in irritable bowel syndrome. Clin Gastroenterol Hepatol 3:237-247 